\title{
Experimental Studies on Breakup and Fragmentation Behavior of Molten Tin and Coolant Interaction
}

\author{
Yankai Li, Zefeng Wang, Meng Lin, Mingjun Zhong, Yueshan Zhou, and Yanhua Yang \\ School of Nuclear Science and Engineering, Shanghai Jiao Tong University, No. 800 Dongchuan Rd., Shanghai, China \\ Correspondence should be addressed to Meng Lin; linmeng@sjtu.edu.cn
}

Received 15 October 2016; Accepted 24 January 2017; Published 28 February 2017

Academic Editor: Oleg Melikhov

Copyright (C) 2017 Yankai Li et al. This is an open access article distributed under the Creative Commons Attribution License, which permits unrestricted use, distribution, and reproduction in any medium, provided the original work is properly cited.

Jet breakup and fragmentation behavior significantly affect the likelihood (and ultimate strength) of steam explosion, but it is very challenging to assess the potential damage to reactor cavity due to general lack of knowledge regarding jet breakup phenomena. In this study, the METRIC (mechanism study test apparatus for melt-coolant interaction) was launched at Shanghai Jiao Tong University to investigate FCI physics. The first five tests on molten tin and water interactions are analyzed in this paper. Significant breakup and fragmentation were observed without considerable pressure pulse, and intense expansion of droplets in local areas was observed at melt temperature higher than $600^{\circ} \mathrm{C}$. The chain interactions of expansion all ceased, however, and there was no energetic steam explosion observed. Quantitative analysis on jet breakup length and debris was studied to investigate the effect of the melt temperature, initial diameter of the jet, and so on. Furthermore, the results of tests were compared with current theories. It is found that melt temperature has strong impact on fragmentation that need to be embodied in advanced fragmentation models.

\section{Introduction}

In a severe accident, ex-vessel steam explosion may occur during melt discharge into a flooded cavity through a large breach in the lower head. It is considered the most concerning fuel coolant interaction (FCI) likely to damage the cavity, with potential consequences for containment integrity [1]. According to classic FCI theory, four distinct phases occur during an explosive FCI: premixing, triggering, propagation, and expansion [2]. The triggering of a spontaneous steam explosion, to a large extent, depends on the jet breakup and fragmentation behavior in the premixing phase. The jet breakup and fragmentation behavior also influences the strength of the explosion. Furthermore, postaccident heat removal is dependent on the condition of debris deposited after fragmentation. To this effect, studies on jet breakup and fragmentation behavior are important in regard to accurate assessment of potential cavity damage and safety in nuclear design and analysis.

Extant melt jet breakup theories indicate that interface instability occurs after the melt is injected into the coolant. Wang et al. found that jet deceleration is responsible for instability [3]. Generally, jet breakup is generated from two types of acceleration, namely, (1) the global acceleration caused by oscillation wave propagation and (2) the local acceleration caused by gas film collapse. Possible causal factors for global acceleration are Rayleigh-Taylor (R-T) instability [2], KelvinHelmholtz (K-H) instability [4], and critical Weber number theory [5], among others; the factor most commonly known to lead to local acceleration is the Marangoni effect [6].

In a notable previous study, Saito et al. conducted a penetration behavior experiment using water jets into freon11 and liquid nitrogen [7]. They found that instability of the leading edge is related to the attenuation of film that results from Taylor instability. Schneider et al. studied the breakup of metal jets penetrating a volatile liquid and noted that jet breakup in a stable condition can result from the steam counter flow but not observe R-T instability [8]. Dinh et al. performed a systematic study of jet breakup using various pairs of simulant liquids to investigate the effects of jet velocity, melt and coolant viscosities, density ratio, and heat transfer [9]. Bürger et al. reported the results of jet breakup models and experimental verification based on KROTOS experiments [5]. They mentioned that K-H instability overestimates the breakup rate. In recent studies, Bang et al. investigate the jet breakup behavior of molten 
material in nonboiling conditions by using wood-metal and found that $\mathrm{K}-\mathrm{H}$ instability is the most probable cause for jet breakup under their experimental conditions [10]. Abe et al. studied the quench behavior of stimulant molten material in low temperature cases. Their results showed that the shape of the molten jet front is similar to the schematic concept of R-T instability, the fragmentation of the molten jet side is related to $\mathrm{K}-\mathrm{H}$ instability, and the stability of the generated fragment is related to the critical Weber number theory $[11,12]$. The effects of solidification were further studied by Iwasawa et al. under the conditions that the interfacial surface temperature was lower than the homogeneous nucleation temperature and minimum film boiling temperature [13]. Real reactor material tests have also been performed by using corium and water to study the quenching behavior, including the small-scale test KROTOS [14], medium-scale test TROI [15], and largescale test FARO [16]. The results of nonexplosion corium tests indicated that significant breakup of the melt into relatively fine debris (about 1.4 to $4.8 \mathrm{~mm}$ ) occurs after corium and water interaction. Crust formation and the possible effects of solidification as the melt permeates the water are also common research objects.

A number of uncertainties persist in regard to predicting FCI phenomena, one of which is the uncertainty of jet breakup length $\left(L_{\text {brk }}\right)$. Several different models of breakup length have been deduced and applied in existing simulation codes. The Saito correlation, which has been applied in JASMINE code and VAPEX code, suggests that $L_{\text {brk }}$ depends on the initial jet diameter, initial velocity, and the density ratio [7]. The correlation used in IKEMIX code, as deduced from K-H theory, suggests the same impact factors of $L_{\text {brk }}$ as the Saito model but is expressed via different formulas. The Meignen model [17], which has been applied in MC3D code, was proposed based on FARO experiments. The impact factors of $L_{b r k}$ in the Meignen model are jet velocity and the viscosity of melt and coolant. According to Epstein and Fauske, $L_{\text {brk }}$ is dependent only on the density ratio of the jet to an ambient fluid without the effect of initial velocity [18]. Jet breakup length remains a problematic factor with various dependencies reflected in the models.

Jet breakup and fragmentation behavior merit further research, as the related mechanisms are far from clear. Supported by a FCI research program in China, we launched a test apparatus called METRIC (mechanism study test apparatus for melt-coolant interaction) at Shanghai Jiao Tong University, in effort to investigate FCI physics, including the breakup mechanism and explosion behavior, and to support the further development of FCI simulation code. This paper discusses the results of the first five tests on molten tin and water interactions, with an objective to study the phenomena and influence factors of breakup and fragmentation behavior. Since the properties of tin are different from realistic corium material, the results of molten tin with water interactions can only be used as the study of basic principles for a better understanding of the FCI phenomena. We built and analyzed a visualization of jet breakup and fragmentation and quantified both breakup length and droplet size throughout the experiments. The effects of melt temperature, jet diameter, and injection velocity were examined in detail as discussed below. Our experimental results are also compared to those obtained via preexisting theories and other experiments.

\section{METRIC Facility}

The METRIC test facility mainly consists of an electromagnetic induction furnace, a seal and release unit, and the test section, as depicted in Figure 1. In addition to these main test systems, other necessary associate devices such as the control system and the cooling systems were designed to support the operation and ensure the safety of both the operators and apparatus.

2.1. Furnace with Seal and Release Unit. Molten melt for our test purposes was produced in an electromagnetic induction furnace which altogether contains a graphite crucible, graphite heater ring around the crucible, and copper pipe inductor. After being melted in the furnace, the melt was injected into the water tank by triggering the melt-release assembly.

The METRIC furnace was designed to work via electromagnetic induction heating. The copper pipe inductor produces a high frequency electromagnetic field with a maximum power of $200 \mathrm{KW}$. The graphite heater ring and the crucible were placed in the center of the electromagnetic filed. Therefore an eddy current is induced in the high-strength graphite materials as to produce heat due to the electromagnetic induction principle. The METRIC furnace has the capability of heating a maximum of $10 \mathrm{~kg}$ melt to $2800^{\circ} \mathrm{C}$ in its crucible. During any heating process, the inside of the furnace must be kept in an inert gas environment to prevent oxidation of the melt or graphite material in the furnace under high temperature. Argon gas is instilled into the furnace continuously during the heating process to provide such an inert gas environment.

Online feeding method was adopted to improve the efficiency of the experiment. An online reload channel is reserved on the top of the furnace. After completing one test, the furnace was fed with new test material once the temperature dropped below $1200^{\circ} \mathrm{C}$ and then was reheated again.

The melt temperature is monitored throughout testing by two infrared thermometers: the first is a two-color infrared thermometer (range: $1100-3000^{\circ} \mathrm{C}$ ) which measures the melt temperature above $1100^{\circ} \mathrm{C}$; the other is a single-color infrared thermometer (range: $300-1300^{\circ} \mathrm{C}$ ) which measures the melt temperature below $1100^{\circ} \mathrm{C}$. Both were calibrated appropriately with deviation within $2^{\circ} \mathrm{C}$ for the low temperature infrared thermometer and $10^{\circ} \mathrm{C}$ for the high temperature infrared thermometer. The thermometers detected the surface temperature of the crucible directly through a detecting channel in the furnace. Since the whole crucible is the heat source for melt, the melt temperature can be regarded as the surface temperature of the crucible in an equilibrium state.

The melt seal and release unit keeps the melt inside the crucible during heating and releases the melt into the water tank after the temperature reaches the expected value. The 


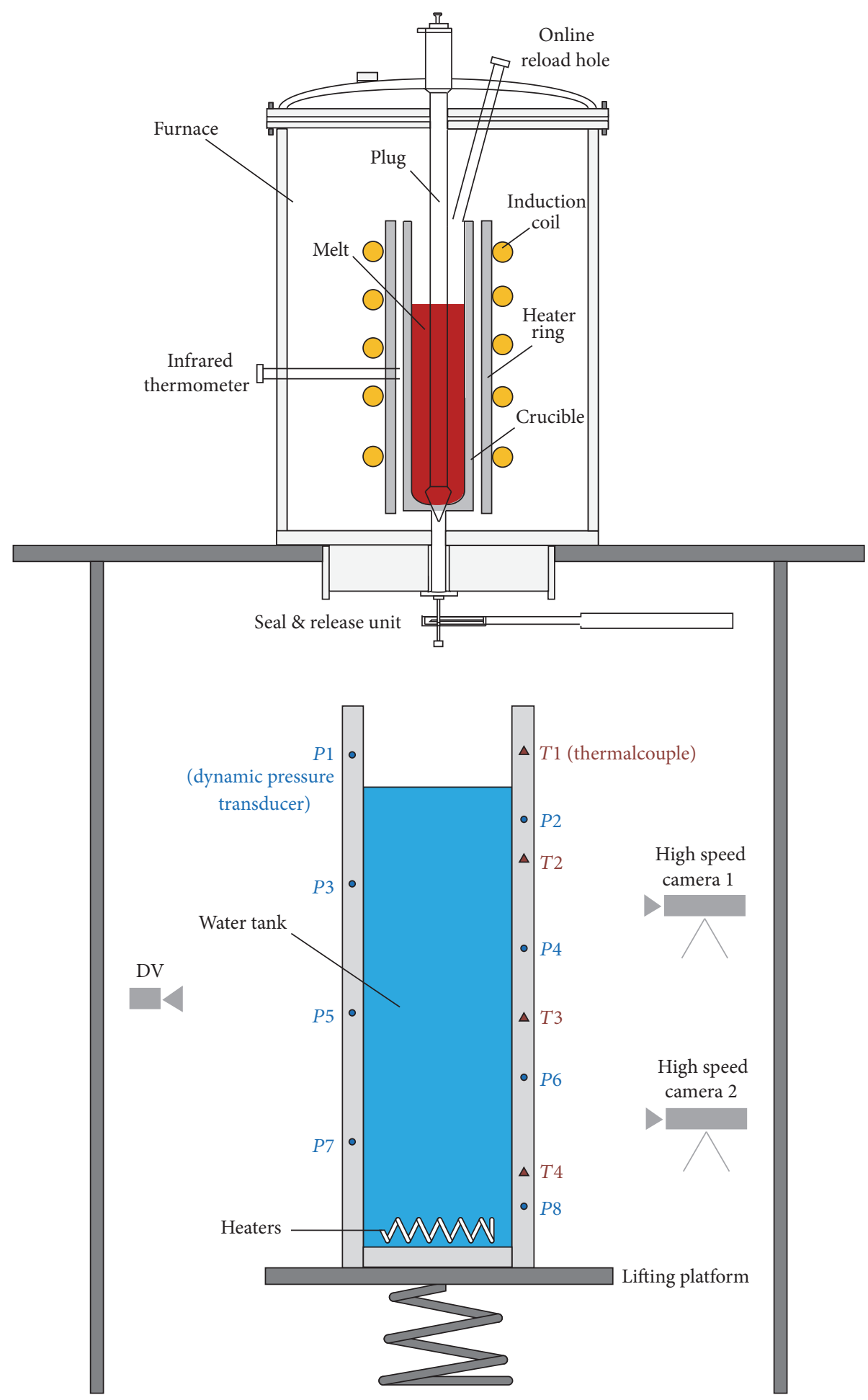

FIGURE 1: Schematic diagram of METRIC facility.

unit consists of a graphite plug, an automatic lifting lever above the furnace, and a gas-seal assembly at the bottom of the furnace. A round release hole is reserved on the bottom of the crucible. During the heating, the plug was inserted into the hole to ensure the melt was sealed. A gas-seal assembly at the bottom of the furnace kept the argon from escaping the furnace.

After the melt was heated to the expected temperature, first, the gas-seal assembly at the bottom of furnace was pulled out, and then the plug was withdrawn to release the melt; 
TABLE 1: Experimental conditions.

\begin{tabular}{|c|c|c|c|c|c|}
\hline Test number & $\mathrm{cl}$ & c2 & c3 & c4-a & c4-b \\
\hline \multicolumn{6}{|l|}{ Melt } \\
\hline Composition & Sn & Sn & Sn & Sn & Sn \\
\hline Released mass (kg) & 1.83 & 2.16 & 1.91 & 1.92 & 2.33 \\
\hline Measured $T_{\text {melt }}\left({ }^{\circ} \mathrm{C}\right)$ & 398 & 612 & 803 & 1018 & 997 \\
\hline Contact $T_{\text {melt }}\left({ }^{\circ} \mathrm{C}\right)$ & 390.4 & 599.9 & 784.8 & 989.4 & 990.2 \\
\hline Superheat $\left({ }^{\circ} \mathrm{C}\right)$ & 159.4 & 368.9 & 553.8 & 758.4 & 759.2 \\
\hline Breach diameter (mm) & 10 & 10 & 10 & 10 & 40 \\
\hline Free fall height (m) & $\approx 0.8$ & $\approx 0.8$ & $\approx 0.8$ & $\approx 0.8$ & $\approx 0.8$ \\
\hline Initial jet velocity (m/s) & 3.82 & 4.09 & 4.12 & 4.49 & 3.94 \\
\hline Weber number & 288.4 & 353.2 & 381.7 & 489.0 & 1494.6 \\
\hline \multicolumn{6}{|l|}{ Water } \\
\hline Height (m) & $\approx 1.0$ & $\approx 1.0$ & $\approx 1.0$ & $\approx 1.0$ & $\approx 1.0$ \\
\hline Temperature $\left({ }^{\circ} \mathrm{C}\right)$ & 22.6 & 22.1 & 23.1 & 23.8 & 23.3 \\
\hline Subcooling $\left({ }^{\circ} \mathrm{C}\right)$ & 77.4 & 77.9 & 76.9 & 76.2 & 76.7 \\
\hline
\end{tabular}

thus, the molten melt was released into the lower test section by gravity.

2.2. The Test Section. The water tank below the furnace is the interaction section in which FCI occurs. Glass windows for visualization were embedded on four sides of the water tank, and measurement instruments (e.g., dynamic pressure sensors and thermocouples) were also implanted in the side walls of the water tank. The area of the tank cross section is $30 \mathrm{~cm} \times 30 \mathrm{~cm}$ and its total height is $120 \mathrm{~cm}$; the glass window in each side is $26 \mathrm{~cm}$ wide and $80 \mathrm{~cm}$ high. Electric heaters were fixed on the bottom of the tank as heat sources. The water tank was placed on a lifting platform in its entirety so that its distance from the furnace is adjustable.

Two high-speed cameras were used to record the meltcoolant interaction process from the glass windows. The recording speed of both cameras was set as $1000 \mathrm{fps}$. One camera with a wide range of perspectives was responsible for the overview shots by recording the whole jet permeating process in the water, and the second camera shot the local area to obtain detailed photographs of FCI. A digital video (DV) was also used to record the entire test process from melt delivery to the interaction in the water tank at a speed of $25 \mathrm{fps}$.

Eight piezoelectric pressure sensors ( $P 1$ to $P 8$ in Figure 1; maximum pressure 103.420 $\mathrm{MPa}$, resonant frequency $>$ $500 \mathrm{kHz}$ ) were implanted in the two side walls of the water tank for dynamic pressure measurement. During testing, the top one was exposed to the atmosphere while the others lay below the water line. All the pressure sensors were carefully calibrated; the maximum permissible error was $2.5 \%$ and the rise time less than $2.0 \mu \mathrm{s}$. Four thermocouples ( $T 1$ to $T 4$ in Figure 1; maximum permissible error of $1^{\circ} \mathrm{C}$ ) were also implanted in another wall of the water tank. The top one measured the atmospheric temperature and the others measured the water temperature. Data acquisition and storage were automatically accomplished via data acquisition (DAQ) system running at a frequency of $40 \mathrm{kHz}$.
2.3. Tests Conditions. Table 1 summarizes the five test conditions in the first stage of METRIC testing, which was characterized by low melt temperature experiments $\left(<1100^{\circ} \mathrm{C}\right)$. The experimental variables at this point were the melt temperature and the initial jet diameter.

Tin served as the simulant corium material and water as the coolant. The low melting point of $\operatorname{tin}\left(231^{\circ} \mathrm{C}\right)$ makes it easy to obtain a series of test conditions with a large range of melt temperature. The melt temperature changed across the first four tests: c1, c2, c3, and c4-a from low to high.

As mentioned above, thermometers placed within the furnace indicated melt temperature. During falling, the melt temperature decreased just before contacting the water. We estimated the contact temperature of melt according to the convection and radiation heat transfer with the surrounding atmosphere. The heat exchanged between the melt and air, $Q$, can be expressed as (1), where $q_{h}$ and $q_{\varepsilon}$ are the heat flux of convection and radiation, respectively, and $t$ is free fall time (the temperature inside the jet is assumed to be homogeneous). Furthermore, (1) can be expanded approximately into (2), which we used to estimate the temperature drop. Convective heat transfer coefficient, $h$, is usually no more than $100 \mathrm{~W} /\left(\mathrm{m}^{2} \cdot \mathrm{K}\right)$ in the forced convection airflow under ambient pressure and here we used its maximum value for the purposes of computation. The emissivity, $\varepsilon$, of the melt is roughly taken as 1.0 as a black body. As a result, there is no significant temperature drop in the melt before falling into the water pool. Temperature drop estimates are 7.6, 12.1, 18.2, 28.6 , and $6.8^{\circ} \mathrm{C}$ for tests $\mathrm{cl}$ to $\mathrm{c} 4$-b, respectively. The estimated contact temperature of melt is determined as listed in Table 1.

$$
\begin{aligned}
Q= & \left(q_{h}+q_{\varepsilon}\right) \cdot A \cdot t \\
c \cdot m & \cdot \Delta T=\left[h \cdot\left(T_{\text {melt }}-T_{\text {air }}\right)+C_{0} \cdot \varepsilon\right. \\
& \left.\cdot\left(\left(\frac{T_{\text {melt }}}{100}\right)^{4}-\left(\frac{T_{\text {air }}}{100}\right)^{4}\right)\right] \cdot A \cdot t .
\end{aligned}
$$




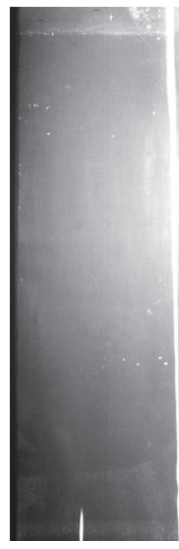

$0.0 \mathrm{~s}$

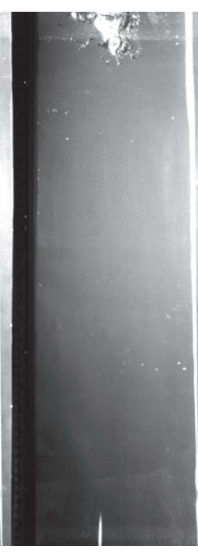

$0.045 \mathrm{~s}$

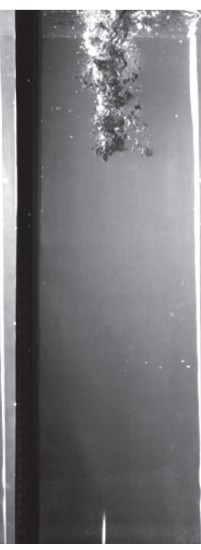

$0.165 \mathrm{~s}$

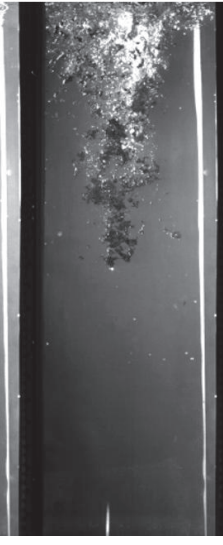

$0.374 \mathrm{~s}$

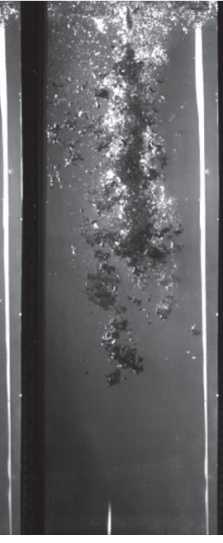

$0.652 \mathrm{~s}$

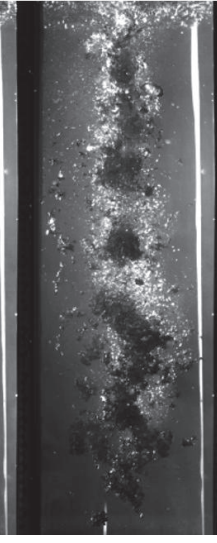

$1.008 \mathrm{~s}$

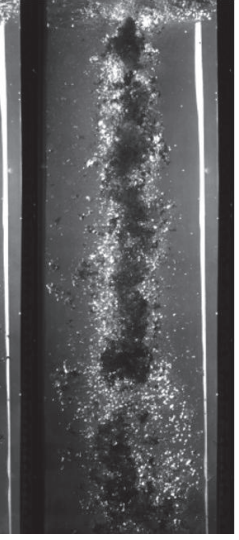

$1.316 \mathrm{~s}$

FIgURE 2: Melt permeating process of test $\mathrm{cl}$.

The experimental variable of the last two tests (c4-a, c4b) was the breach diameter of the crucible, either $10 \mathrm{~mm}$ or $40 \mathrm{~mm}$. The other conditions of all five tests were kept constant: the mass of molten tin is about $2 \mathrm{~kg}$, the release height from the outlet of melt to the water surface is about $80 \mathrm{~cm}$, the water temperature is about $23^{\circ} \mathrm{C}$, and the cross section area of the water tank is $30 \mathrm{~cm} \times 30 \mathrm{~cm}$. Initial jet velocity and the Weber number are also important initial conditions related to jet breakup and fragmentation and thus are listed in the table among other variables. The superheat of melt and subcooling of water are listed as scaling factors of the temperature in the tests, as well.

\section{Visualization of Jet Behavior}

3.1. Jet Breakup Behavior. Figure 2 shows the jet permeating process of test $\mathrm{cl}$ during which $390.4^{\circ} \mathrm{C}$ molten tin was injected into water. Premixing as well as significant breakup was clearly observed, but there was no steam explosion observed throughout the whole FCI process. The melt jet began to break up once being injected into water, falling with a scattering of droplets. Droplets were stripped from the side of jet in significant proportion, most likely a result of K-H instability. The wave on the side of jet was slightly similar to K$\mathrm{H}$ instability, that is, not particularly obvious (the mechanism of breakup was further discussed in Section 4.2.2). The bubbles shown in Figure 2 indicated that vapor was produced around the melt. There was a light packet of bubbles close to the pool surface which is supposed to be the air gotten captured as jet entered the water. The air bubbles may mix with the steam and travel down with the jet. In the middle part of the water pool, bright gas bubbles broke into an abundance of smaller bubbles that spread sideways, and then moved upward. In the lower part of the water pool, most of the bubbles were, assumedly, steam produced by the vaporization of water.

The amount of bubbles effectually represents the intensity of heat transfer. As the jet permeated into the water, more bubbles were produced and accumulated in the water pool before escaping from the water surface. Due to the emergence of vapor, the melt released into the water subsequently had fewer chances to contact liquid water directly and maintained a high temperature before falling into a deeper position. For this part of melt, intense quenching took place in the lower part of the water tank where direct contact was more likely to occur. This produced a large amount of bubbles in the bottom of the water pool when the jet front had already fallen to the bottom (at $1.316 \mathrm{~s}$ ).

Figure 3 displays the jet behavior of test c4-b with melt temperature of $990.2^{\circ} \mathrm{C}$ and release diameter of $40 \mathrm{~mm}$. The melt showed significant breakup and fragmentation as the jet permeated the water. The jet kept very bright until falling into the middle part of the water tank, indicating that melt temperature was still very high at that point. After quenching during injection process, the jet became dark in the middle part of the water tank. Droplets and fragments were striped out around the bright jet; the fragments were fine and highly atomized as they scattered into the water. According to the breakup theory of Bürger et al. [5], the jet forms an atomization regime when the Weber number exceeds 100. The Weber number of each of the five tests, as listed in Table 1, exceeded 100. Although both $\mathrm{cl}$ and c4-b had atomization breakup, the atomization in c4-b was much finer than that of cl. A major cause of this observation was that test of c4-b had a great Weber number, 1494.6, compared to 288.4 for test $\mathrm{cl}$. Jet and droplets in test $\mathrm{c} 4$-b were more disperse and occupied more space in the water. Obviously, the fragments of $\mathrm{c} 4$-b were even finer than those $\mathrm{cl}$, which was conducted at low temperature.

As mentioned above, there was no identifiable pressure pulse of steam explosion observed in any of the five tests.

Droplets were stripped from the side of jet during jet permeation process as a result of $\mathrm{K}-\mathrm{H}$ instability. As shown in Figure 2, although there were waves in the side of jet, they were not obvious enough to conclude that they were the morphology of K-H instability. In Figure 3, suspected K$\mathrm{H}$ instability morphology is observable in the side of the jet close to water surface at $0.332 \mathrm{~s}, 0.826 \mathrm{~s}$, and $1.435 \mathrm{~s}$ (which are circled). Conversely, R-T instability was barely observable in the leading edge of the jet in the photos. Since both the superheat and velocity of the melt are high in our tests, 


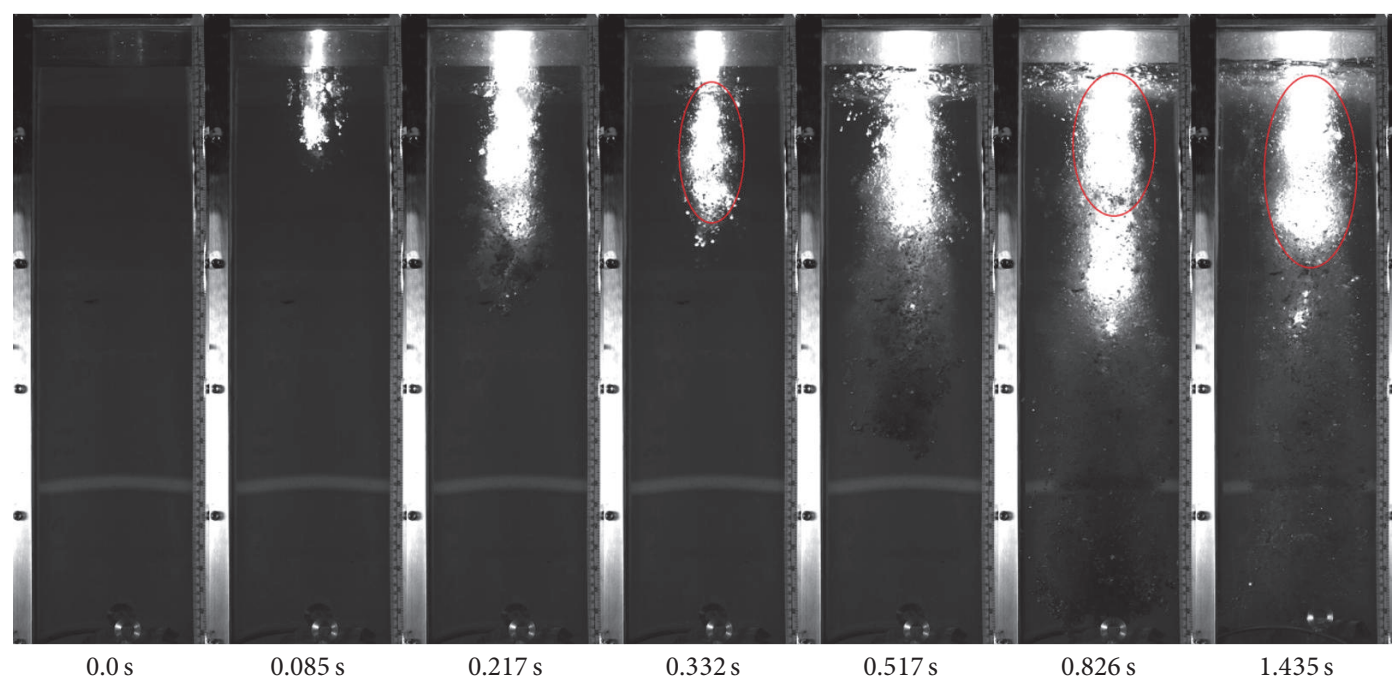

FIGURE 3: Melt permeating process of test c4-b.

it was especially difficult to observe any single instability mechanism via visualizations. The essence of jet breakup and fragmentation will be discussed further with comparison with instability theories in Section 4.2.2.

3.2. Local Expansion of Droplets. In the tests with melt temperature higher than $600^{\circ} \mathrm{C}(\mathrm{c} 2, \mathrm{c} 3, \mathrm{c} 4-\mathrm{a}$, and $\mathrm{c} 4-\mathrm{b})$, distinct and intense expansion of droplets/jet in some local areas was frequently observed during the jet permeation process, which was likely caused by the collapse of vapor film on droplets. The higher the melt temperature, the more frequent the local expansion phenomenon. In order to obtain detailed images of the expansion process, a specific highspeed camera was placed against the lower part of the water tank, where droplet expansion was more likely to occur. Figure 4 shows one of the instances of local expansion process of droplets that we observed in test c4-b. A video is also provided as the supplementary material available online at https://doi.org/10.1155/2017/4576328 with the name of "c4-b Local Expansion.” Interestingly, there was no considerable pressure pulse detected in this process though four waves of intense expansion in local area were observed. Red rings in the $0 \mathrm{~ms}$ image cycle outside the area that would expand; each ring was numbered according to expansion sequence.

A spontaneous collapse of vapor film appeared to take place in ring 1 , followed by the direct contact between melt and water, which led to a rapid expansion of the droplet in this area from $0 \mathrm{~ms}$ to $4 \mathrm{~ms}$. Next, there was secondary expansion of the droplets following the first one in ring 2 just beside ring 1. The secondary expansion lasted from $5 \mathrm{~ms}$ to $11 \mathrm{~ms}$ and the swelling was more violent than that of the first expansion. This was followed by droplets shrink in the adjacent areas (ring 3 from $11 \mathrm{~ms}$ to $13 \mathrm{~ms}$ ), which was likely caused by the collapse of an increased amount of vapor films. The collapse is probably caused by the pressure pulse produced in the previous expansion. A third expansion in a larger area occurred following the shrinkage (ring 3 from $14 \mathrm{~ms}$ to $17 \mathrm{~ms}$ ), like an outburst after the direct contact between melt and water. Finally, further shrinkage and a fourth rapid expansion of droplets were observed again (18 ms to $25 \mathrm{~ms}$ ) in ring 4 at a distance. To make the expansion process clearer, droplet zone sizes in the four rings (the size of the boundary of the droplets in the four zones) are drawn as function of time in Figure 5 (in addition, a video of the expansion process is also supplied with the paper). In effect, the size of droplets in four rings shows intense, successive changes.

We found that a pressure wave was produced with the first collapse of steam film, and then the propagation of the pressure wave triggered a series of rapid expansions in adjacent areas. The whole process lasted about $25 \mathrm{~ms}$, during which four waves of expansion were observed successively. By the end of the process, the chain interaction of expansion ceased and there was no further triggering of steam film collapse. We also found that the local expansion was more likely to occur in the scattered droplets than in the jet. The chain interactions of expansion likely ceased due to (1) the attenuation of the pressure wave during its propagation; and (2) the fact that the growing of vaper film around the droplet made it more stable after the expansion progress. Although no considerable steam explosion was observed, the local small-scale expansion did promote the fragmentation of droplets.

The thermal interaction zone (TIZ) theory shows that there would be a steam explosion in test c4-b in which the tin melt temperature reaches $1000^{\circ} \mathrm{C}$ [19]. However, as mentioned above, we only observed numerous local smallscale steam explosions in the visualization but no large-scale steam explosion. Comparing the TIZ theory and our test, the difference may come from two main reasons. One is that the test conditions of our tests are different with the tests that TIZ theory is based on. Our test is relatively of big scale ( $2 \mathrm{Kg}$ tin jet, in a $30 \mathrm{~cm} \times 30 \mathrm{~cm}$ water tank) compared to the smallscale test (single tin droplet) of Dellforce that proposed the TIZ theory. The local small-scale steam explosions in our tests are similar to the phenomena of single tin droplet test 


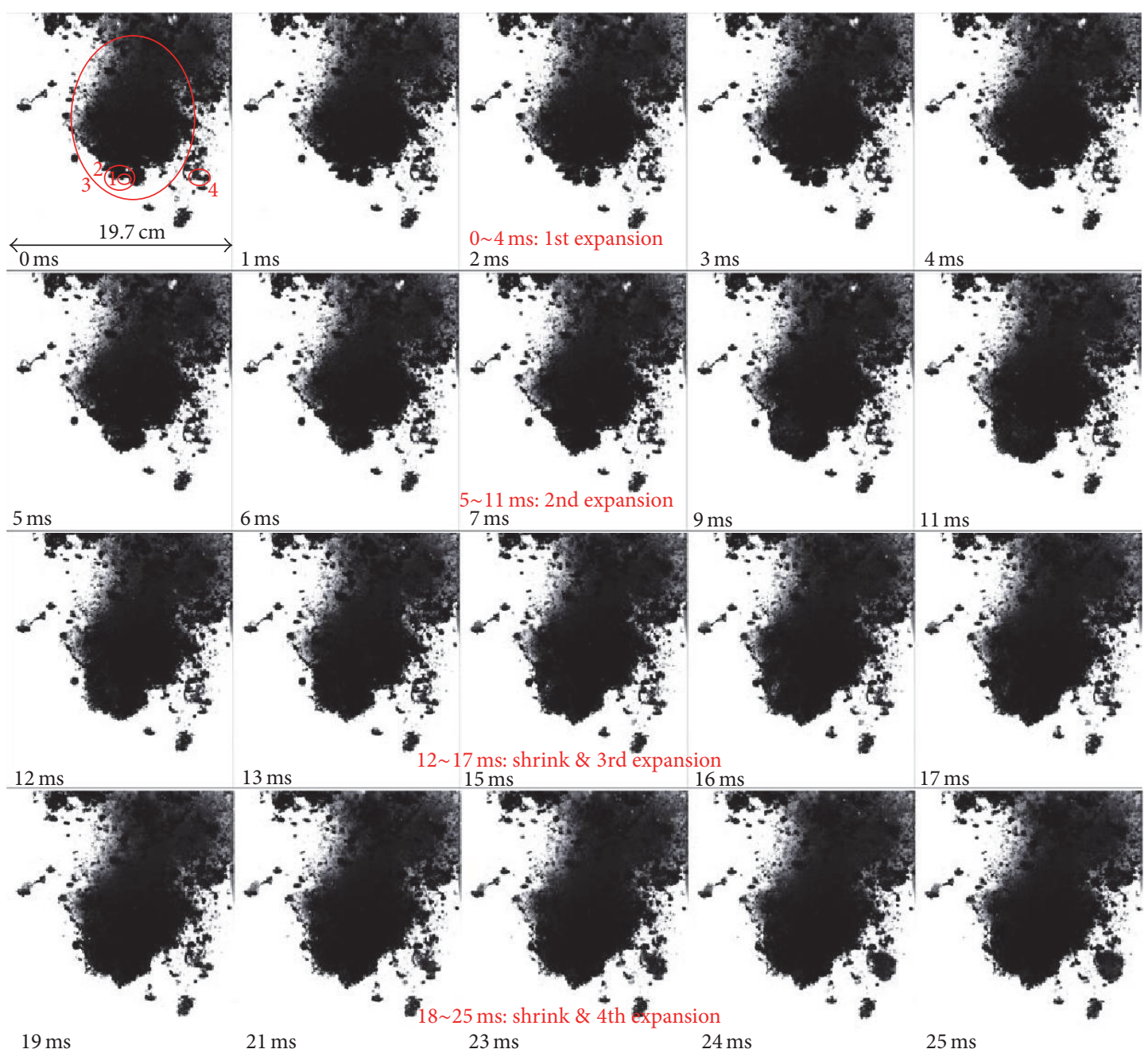

Figure 4: Local expansion phenomena in test c4-b.

that TIZ theory is based on. The other reason may be the attenuation of the pressure wave during its propagation in a big water tank as mentioned above. The pressure sensors installed in the wall of water tank showed that the pressure had been indistinguishable from the background normal pressure. The attenuation of the pressure wave may prevent the local small-scale steam explosion to become a large-scale steam explosion.

\section{Quantitative Results Analysis}

\subsection{Breakup Length}

4.1.1. Experimental Breakup Length. The location of jet leading edge was clear in the visual images. During the recognition of jet leading edge, the falling of a spot of scattered melt in the beginning of melt release is ignored artificially; the leading edge location of stable continuous falling of melt was analyzed. Once the elevation of jet leading edge is confirmed, we were able to calculate the velocity by differentiating the elevation.
The initial jet velocity is the average difference of the leading edge heights during the $5 \mathrm{~ms}$ before it falls into the water. At the early stage of jet permeation, the velocity is the average difference of $10 \mathrm{~ms}$; later, the permeating velocity is the average difference of $20 \mathrm{~ms}$. The time is selected based on the fact that the jet slowed as it fell during permeation. Figure 6 shows the jet front elevation of the five tests and their permeation velocities.

Experimental jet breakup length could be defined according to the changes in jet leading edge elevation. We used an estimation method for breakup length similar to those used in work by Magallon and Hohmann [20] and Matsuo et al. [21]. As the jet front descended with time into the water, it underwent two phases. In the first phase, after the melt was injected into the water, the track of jet front took a parabola shape. In the second phase, it slows down and formed a roughly straight line. Correspondingly, the descending velocity of jet front was relatively high but trended down in the first phase and then remained steady at a lower velocity in the second phase. The specific point at which the jet velocity reached the terminal speed was identified as the end of the breakup process. Jet breakup length is the distance 


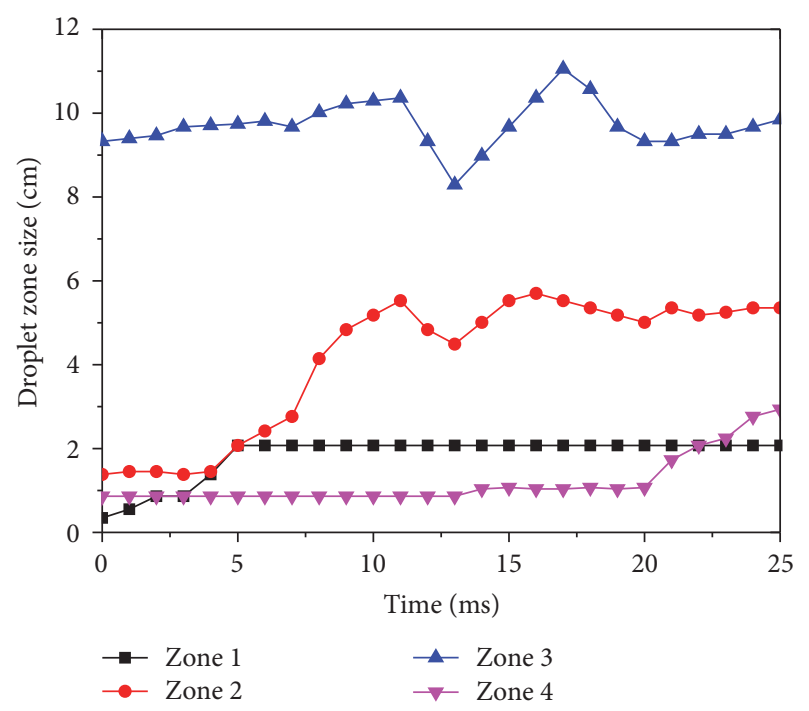

FIGURE 5: Change of droplet zone size in the expansion process.

from the stable breakup front to the surface of water. The blue dashed lines in Figure 6 are the auxiliary lines used to ascertain the terminal speed and breakup length. Manual error is introduced during the determination of the terminal speed, which we found to be within $5 \%$ after verifying the results of different person.

In test $c 3, c 4-a$, and c4-b, obvious jumps of velocity are found in Figure 6 (at about $0.03 \mathrm{~s}$ for test $\mathrm{c} 3,0.08 \mathrm{~s}$ for test $\mathrm{c} 4$ $\mathrm{a}$, and $0.02 \mathrm{~s}, 0.04 \mathrm{~s}$, and $0.07 \mathrm{~s}$ for $\mathrm{c} 4-\mathrm{b}$ ). A local explosion might happened at that point which accelerates the melt front instantaneously. This is consistent with the visualization phenomena that the interaction is fiercer with higher melt temperature and local steam explosion is observed when the melt temperature is higher than $600^{\circ} \mathrm{C}$. Especially in test c4$\mathrm{b}$, three jumps of velocity are found while numerous local explosions are observed in the visualization.

4.1.2. Breakup Length Theory. The ratio of experimental breakup length to initial diameter $(L / D)$ is discussed in this section. Figure 7 presents the comparative results of experimental $L / D$ against theoretical values, as well as the FARO tests [19], PREMIX tests [22], and the tests by Matsuo et al. [21]. According to current breakup theories, both the Saito model and the IKEMIX code model assert that $L / D$ ratio varies with Froude number, that is, related to the initial velocity. Epstein's correlation, however, suggests that $L / D$ varies with the density ratio of the jet and surrounding fluid without the influence of velocity. Matsuo found that the interaction between low temperature $\mathrm{U}$-alloy and water is consistent with the estimate of Epstein's correlation in the regime of factor $E_{0}=0.05$ and 0.1 , which they verified experimentally. Four of our METRIC tests produced results also in accordance with Epstein's correlation, while test c4-a showed a slight deviation. We also observed a trend in which $L / D$ increased with Froude number for the results of METRIC tests.

Under our test conditions, the Saito model fairly significantly overestimated the breakup length. The breakup lengths of the Saito model in all five tests were about double those of the METRIC test results. The estimations of the IKEMIX model, however, were consistent with the experimental breakup length under our test conditions; the results of experimental $L / D$ distributed along the sides of the IKEMIX model estimations. Considering the $L / D$ variation trend, our experimental results were in closer accordance with the IKEMIX breakup model than Epstein's correlation. This suggests that the Froude number or the effect of velocity is critical consideration in terms of accurately modeling jet breakup behavior.

\subsection{Debris Analysis}

4.2.1. Temperature Effect on Fragmentation. Figure 8 shows images of the debris collected after molten jet quenching, at melt temperatures from $390.4^{\circ} \mathrm{C}$ to $989.4^{\circ} \mathrm{C}$. In the low melt temperature test, there was a large amount of massive debris bonded together into a bulk, fluffy structure. The bulk surface was rough and full of metal filaments and voids. As the melt temperature increased, the debris mostly presented as fine granules or even powder with a smooth surface. The melt was finely fragmented by the end of the high temperature test, which is consistent with the visual observation that FCI grew more intense as the melt temperature increased. In short, the melt temperature exerted significant influence on jet and droplet fragmentation.

The size distribution of droplets is important information in any FCI study, as it determines the heat transfer area. We conducted quantitative analysis of the debris remaining after our tests to determine the droplet size distribution. Statistics of the mass fractions after the five tests are illustrated in Figure 9. As melt temperature increased, the proportion of debris larger than $10 \mathrm{~mm}$ decreased while that smaller than $4 \mathrm{~mm}$ increased; in effect, droplets were more finely fragmented as melt temperature increased.

We defined the mean diameter of debris as the weighted average of different sizes of debris:

$$
d_{m}=\sum p_{i} d_{i}
$$

where $d_{m}$ is the mean diameter and $p_{i}$ is the weight percentage of the debris with diameter of $d_{i}$. For a FCI test, the smaller the mean diameter, the higher the degree of fragmentation and the bigger the total area of heat exchange. The mean diameters obtained after all five tests are shown in Figure 10. As the melt temperature increased, the mean debris diameter considerably decreased. High melt temperature promoted the fragmentation of melt droplets. On the one hand, the amount of time that jet needed to cool down was prolonged as melt temperature increased, which also means that the thermal fragmentation time was extended. On the other hand, the surface tension of the droplet increases as its temperature decreases, a phenomenon called the Marangoni effect [6]. During the low temperature test, high surface tension prevented jet and droplet breakup. During the high temperature test, however, lower surface tension of jet and droplet allowed them to break apart more easily. 

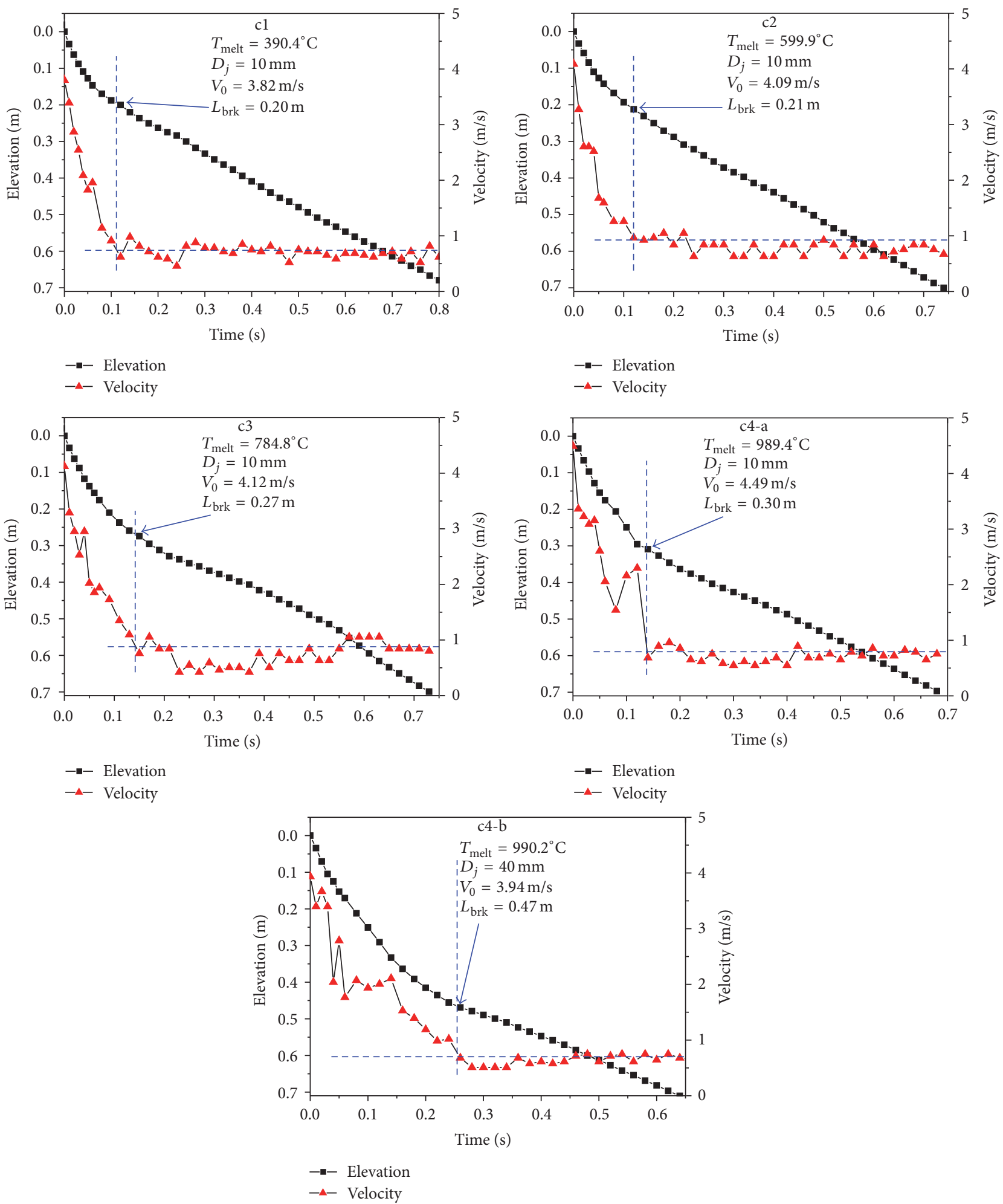

FIGURE 6: The elevation of jet front and injection velocity.

Solidification and instability on the melt-coolant interface also contributed substantially to the temperature effect we observed. In the low temperature test $\mathrm{cl}$, solidification of the droplet surface likely prevented the fine melt fragmentation. The superheat degree of molten tin in test $\mathrm{cl}$ was only $159.4^{\circ} \mathrm{C}$ that it readily solidified after quenching in the water. Solidification made the melt water interface stable and prevented further fragmentation of droplets. In actual corium-water interaction, solidification of melt surface is fairly likely to occur due to the fact that the melting point 
TABLE 2: Comparison of median diameter and estimated wavelength of theories.

\begin{tabular}{lccccc}
\hline Test & $\begin{array}{c}\text { Transient velocity } \\
\mathrm{m} / \mathrm{s}\end{array}$ & $\begin{array}{c}\text { Median } D \\
\mathrm{~mm}\end{array}$ & $\begin{array}{c}\mathrm{R}-\mathrm{T} \\
\mathrm{mm}\end{array}$ & $\begin{array}{c}\text { K-H } \\
\mathrm{mm}\end{array}$ & $\begin{array}{c}\text { Critical Weber theory } \\
\mathrm{mm}\end{array}$ \\
\hline $\mathrm{c1}$ & $3.82 \sim 0.75$ & 7.7 & 30.94 & $0.23 \sim 6.05$ & $0.58 \sim 15.16$ \\
$\mathrm{c} 2$ & $4.09 \sim 0.92$ & 6.8 & 30.94 & $0.20 \sim 4.02$ & $0.51 \sim 10.07$ \\
$\mathrm{c3}$ & $4.12 \sim 0.58$ & 4.8 & 30.94 & $0.20 \sim 10.11$ & $0.50 \sim 25.34$ \\
$\mathrm{c4}-\mathrm{a}$ & $4.49 \sim 0.79$ & 4.1 & 30.94 & $0.17 \sim 5.45$ & $0.42 \sim 13.66$ \\
$\mathrm{c4}-\mathrm{b}$ & $3.94 \sim 0.73$ & 4.2 & 30.94 & $0.21 \sim 6.38$ & $0.55 \sim 16.00$ \\
\hline
\end{tabular}

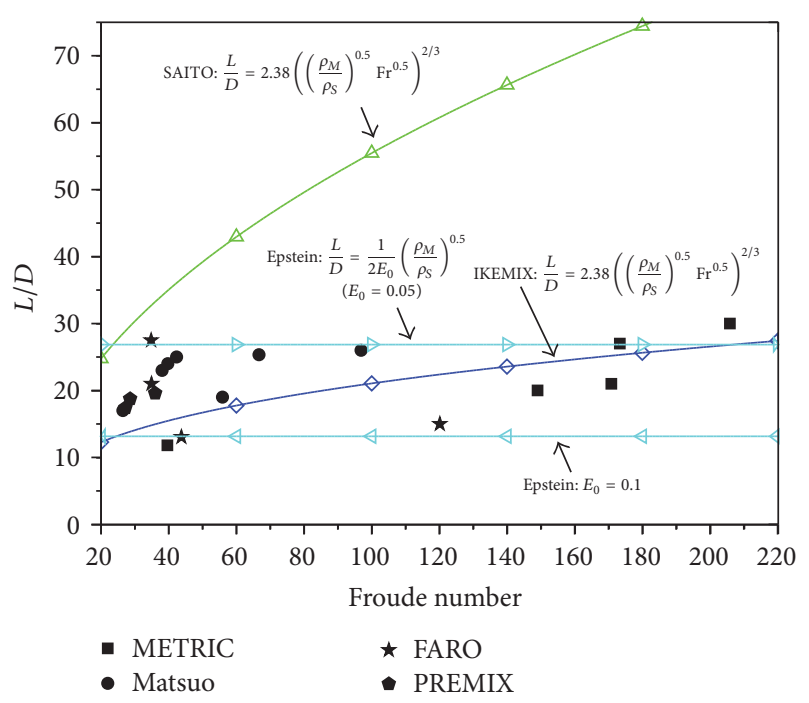

FIGURE 7: Comparison of experimental $L / D$ with models and other experiments.

of corium is very high. In the relatively high temperature tests, melt solidification was averted since the superheat was very high in the beginning of melt-coolant interaction. On the contrary, distinct and intense expansion of droplets in some local areas was observed, again, most likely to be caused by the collapse of vapor film on some droplets. The local intense expansion caused by vapor film instability promoted the droplets fragmentation.

4.2.2. Comparison with the Instability Theory. Interface instability occurs after the melt is injected into the water. The factors leading to jet breakup are mainly R-T instability, K$\mathrm{H}$ instability, and critical Weber number theory, among some others.

During the jet permeating process, we observed K-H instability morphology in test $c 4-b$, but no direct visualization information supported R-T instability or critical Weber number theory. To explore the mechanism of jet breakup and fragmentation in our tests, we compared the mean diameter of debris to the estimates of theories, as shown in Figure 11.

The mean diameters of all five tests were located between the estimate of R-T instability and critical Weber theory. Considering that the jet permeating velocity decreased after being injected into the water, the estimated wavelength of critical Weber theory and K-H instability should have been an interval from the initial injection velocity to the ultimate velocity. The initial injection velocity values of the five tests were $3.82 \sim 4.49 \mathrm{~m} / \mathrm{s}$ while the ultimate velocity was about $0.8 \mathrm{~m} / \mathrm{s}$. The interval estimates of theories for the five tests, from $0.8 \mathrm{~m} / \mathrm{s}$ to $4.49 \mathrm{~m} / \mathrm{s}$, are marked by the bold lines in Figure 11 (while the other parts beyond the interval are dashed line). With the observed interval, the wavelength of critical Weber theory covered the mean diameter of all five tests.

Our comparison of the mean diameter and estimated wavelength among the several theories is also listed in Table 2. The wavelengths of $\mathrm{R}-\mathrm{T}, \mathrm{K}-\mathrm{H}$, and critical Weber theory were estimated as an interval corresponding to the interval of transient velocity in the tests. The italic data in Table 2 indicates that the estimated wavelength can cover the mean diameter of the test. The estimate of critical Weber theory covered the results of all five tests while the estimate of K$\mathrm{H}$ instability theory matched with the results of only three tests, c3, c4-a, and c4-b. It is worth noting that the estimated wavelength interval of critical Weber theory is more than double that of $\mathrm{K}-\mathrm{H}$ instability due to its much wider range. The mean diameter values of the five tests were closer to the estimated wavelength of K-H instability, however. Based on these results, both the critical Weber theory and the K-H instability are most likely mechanisms for the breakup and fragmentation we observed during our tests.

As mentioned above, melt temperature appeared to assert a significant influence on jet and droplet fragmentation; nevertheless, the temperature effect has not been well embodied in current instability theories or fragmentation models in FCI codes. In the existing theories, melt temperature only impacts the wavelength indirectly by influencing the surface tension, the density of melt, and surrounding fluid. From tests c1 to c4-a (melt temperature is from $390.4^{\circ} \mathrm{C}$ to $989.4^{\circ} \mathrm{C}$ ), the changes in density and the surface tension were not as significant as the increases in melt temperature. This observation makes temperature a rather weak impact factor with regard to instability, even in the thermal fragmentation theory of R-T instability. In critical Weber theory and K$\mathrm{H}$ instability theory, which are both induced based on hydraulic fragmentation, wavelength is mainly determined by relative velocity. Because the difference in velocity among our five tests was small, the estimated wavelength intervals of the five tests were similar. The estimated results are not a good reflection of the significant impact of temperature on fragmentation. The temperature effect on fragmentation needs further consideration in FCI fragmentation model. As is discussed in Section 4.2.1, solidification of low superheat melt and local expansion of high temperature melt may have significantly influenced the breakup and fragmentation we 


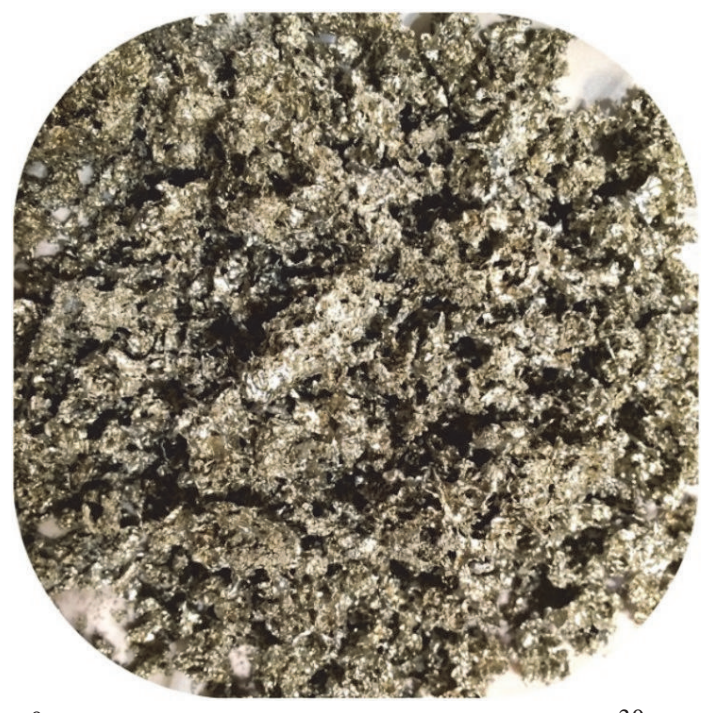

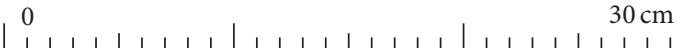

(a) $\mathrm{c} 1390.4^{\circ} \mathrm{C}$

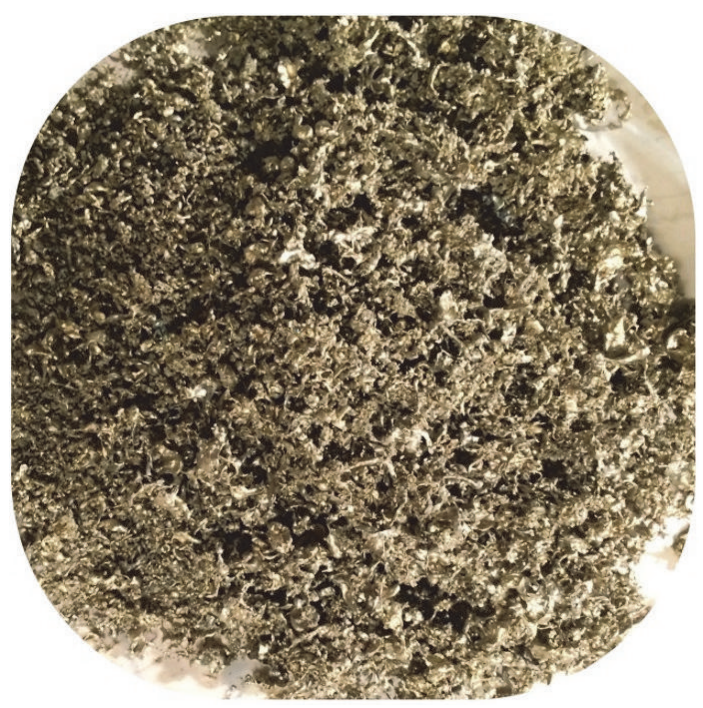

0

(c) $\mathrm{c} 3784.8^{\circ} \mathrm{C}$

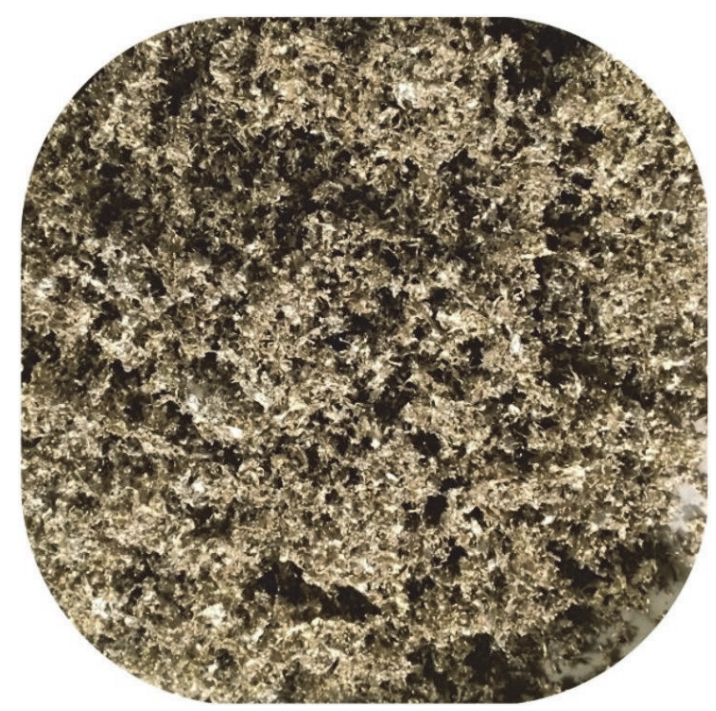

0

(b) $\mathrm{c} 2599.9^{\circ} \mathrm{C}$

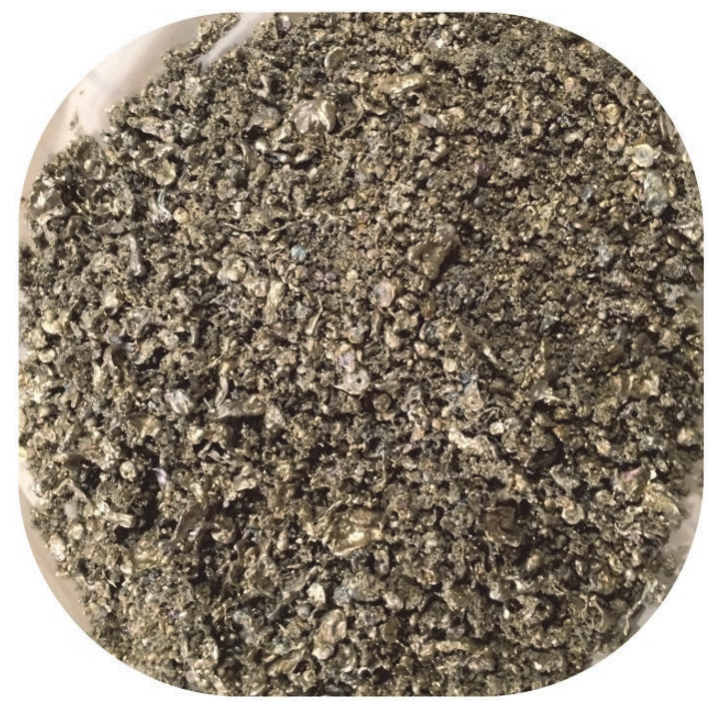

$30 \mathrm{~cm}$

FIGURE 8: Debris collected after fragmentation.

observed, though neither is sufficiently modeled by current exiting theories. Especially, in the simulation code of FCI, current models could not reflect the strong effect of temperature, which may bring inaccurate result of heat exchange area, energy conversion efficiency, and the peak pressure of steam explosion. Further development of theories and models based on the phenomena we observed is necessary to fully and accurately reflect the temperature effect.

\section{Summary}

Melt breakup and fragmentation behavior were investigated in this study based on five tests on molten tin and water interactions conducted at the METRIC facility. Four of the tests were run with different melt temperatures from $390.4^{\circ} \mathrm{C}$ to $990.2^{\circ} \mathrm{C}$ with breach diameter of $10 \mathrm{~mm}$ and the fifth was run with a larger breach of $40 \mathrm{~mm}$. Visualizations of the jet permeation process were analyzed and the effects of melt temperature, jet diameter, and initial velocity were discussed at length. We also compared our results against those produced by preexisting theories. Our most notable conclusions can be summarized as follows:

(i) Visualization of jet permeating process showed that significant breakup and fragmentation took place, with shining gas bubbles around it. In the tests with temperature higher than $600^{\circ} \mathrm{C}$, distinct and intense expansion of a series of droplets at certain local areas 

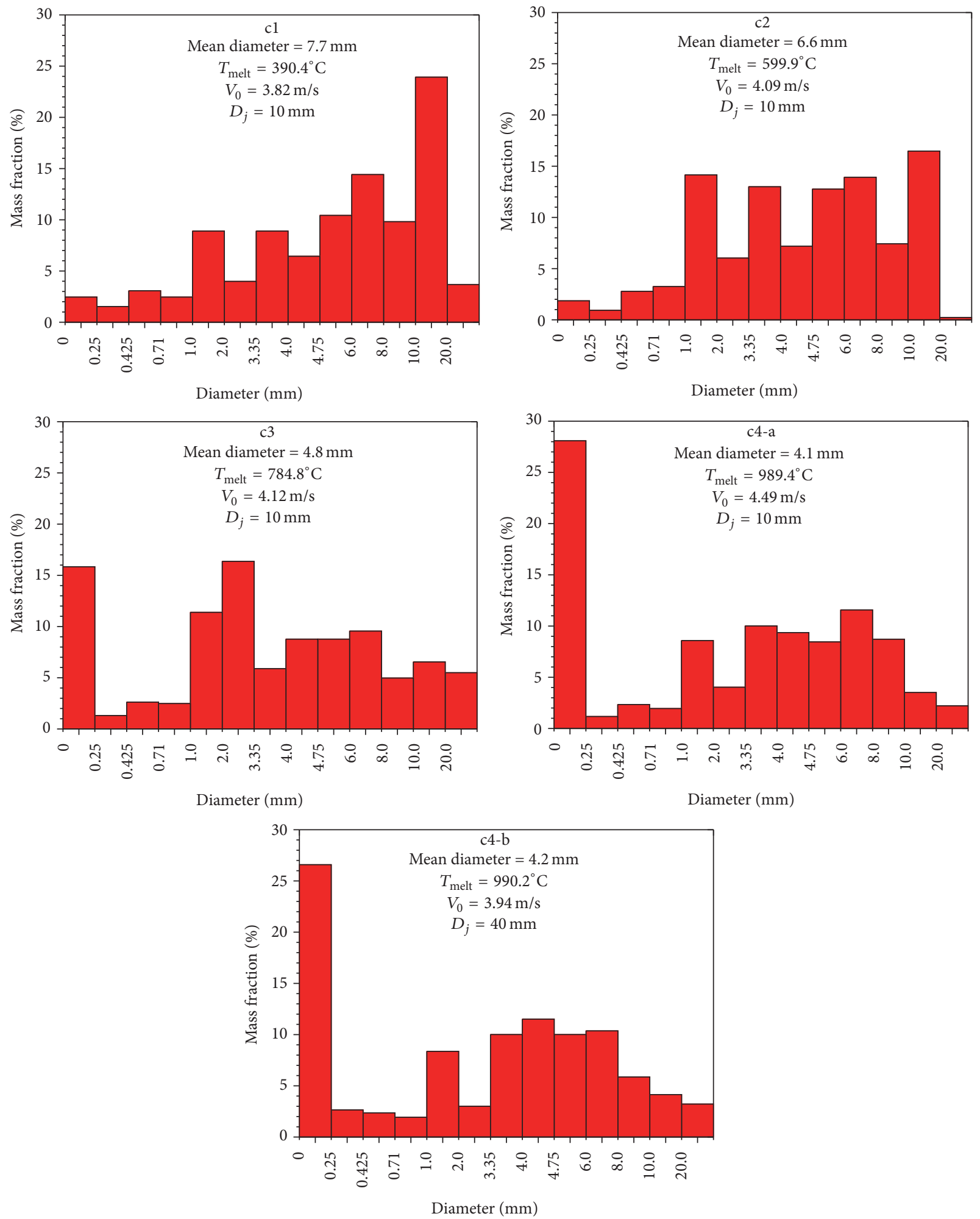

FIGURE 9: Statistic of the mass fraction for the five tests.

were observed, which we believed to have been caused by the collapse of vapor film. Propagation of the pressure wave triggered a series of rapid expansions in adjacent areas; however, by the end of the process, the chain interaction of expansion ceased and there was no further triggering of vapor film collapse; furthermore, there was no energetic steam explosion observed. 


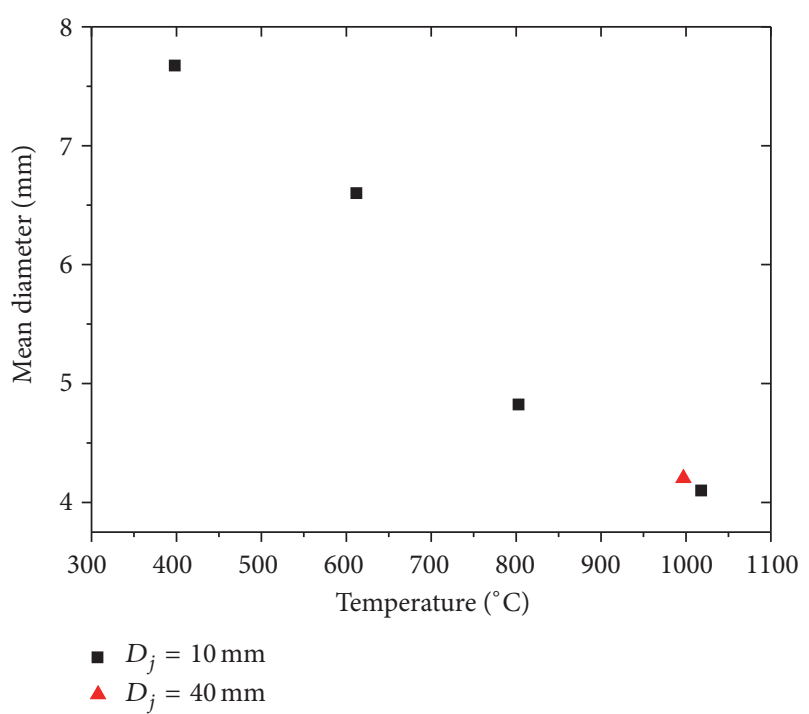

Figure 10: Mean debris diameter for the five tests.

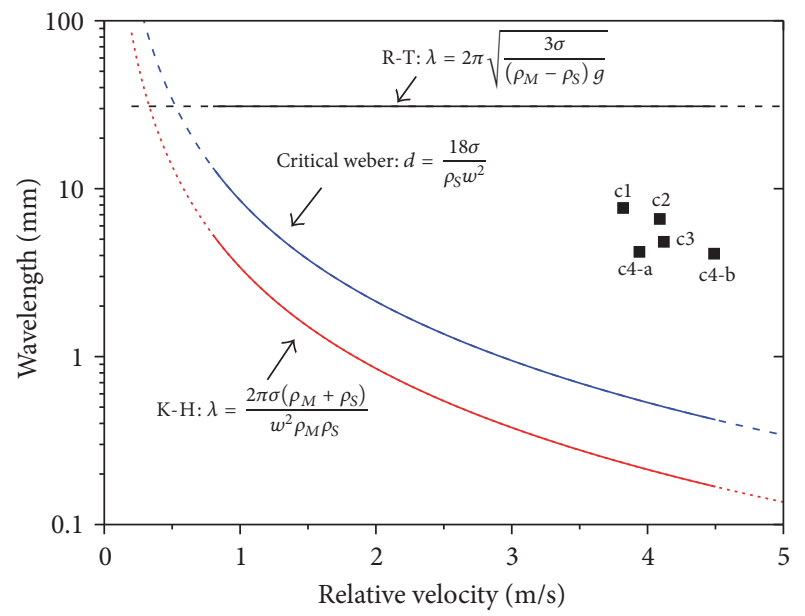

FIGURE 11: Mean diameter of tests and estimated wavelength of theories.

(ii) Quantitative analysis of experimental breakup length showed that the jet diameter elongated the breakup length significantly. The $L / D$ ratio of our tests varied with the Froude number. Comparison between the experimental $L / D$ and the estimates produced by other breakup theories showed that the IKEMIX model is close to the test results in that the effect of initial velocity is included appropriately.

(iii) Debris analysis indicated that molten tin temperature has a strong impact on the melt fragmentation. As melt temperature increased, the mean diameter of debris considerably decreased. In the low melt temperature test, melt surface solidification prevented further fragmentation, while, in the high temperature test, intense expansion of droplets in local area promoted the fragmentation. The jet diameter, which elongated the breakup length significantly, however, had no significant effect on debris size.

(iv) Instability analysis based on debris statistics showed that both critical Weber theory and K-H instability were most likely mechanisms for the breakup and fragmentation we observed during tests. It is crucial to note that the significant temperature impact of temperature on fragmentation is not well embodied in currently existing instability theories or models and thus merits further study.

However, since the properties of tin are different from realistic corium material, the results of molten tin with water interactions can only be used as the study of basic principles for a better understanding of the FCI phenomena. It is still difficult to estimate the consequence of coriumwater interaction based on the result of simulant material interaction by current FCI theories. Therefore, in a further study, the corium-water interaction should be performed for a better understanding of the FCI phenomena in real nuclear reactor.

\section{Nomenclature}

Abbreviations

DAQ: Data acquisition

DV: $\quad$ Digital video

FCI: $\quad$ Fuel coolant interaction

K-H: Kelvin-Helmholtz

METRIC: Mechanism study test apparatus for melt-coolant interaction

R-T: $\quad$ Rayleigh-Taylor

TIZ: Thermal interaction zone.

Symbols

c: $\quad$ Specific heat capacity $(\mathrm{J} /(\mathrm{kg} \cdot \mathrm{K}))$

$m$ : Mass $(\mathrm{kg})$

$\Delta T:$ Temperature drop $(\mathrm{K})$

$h$ : Convective heat transfer coefficient $\left(\mathrm{W} /\left(\mathrm{m}^{2} \cdot \mathrm{K}\right)\right)$

$\varepsilon$ : Emissivity

$\lambda$ : Wavelength $(\mathrm{m})$

$\sigma: \quad$ Surface tension $(\mathrm{N} / \mathrm{m})$

$\omega: \quad$ Relative velocity $(\mathrm{m} / \mathrm{s})$

$\rho: \quad$ Density $\left(\mathrm{kg} / \mathrm{m}^{3}\right)$

$\mathrm{We}_{c}$ : Critical Weber number

L: $\quad$ Breakup length $(\mathrm{m})$

$d$ : Droplet diameter $(\mathrm{m})$

$D$ : Jet diameter $(\mathrm{m})$

Fr: Froude number

$V: \quad$ Velocity $(\mathrm{m} / \mathrm{s})$

$p$ : Percentage

$q$ : $\quad$ Heat flux $\left(\mathrm{W} / \mathrm{m}^{2}\right)$

g: Acceleration of gravity $\left(\mathrm{m} / \mathrm{s}^{2}\right)$

$\mathrm{C}_{0}$ : Blackbody radiation coefficient $(\mathrm{W} /(\mathrm{m} \cdot \mathrm{K}))$

$E_{0}$ : Epstein factor. 


\author{
Subscripts \\ $j$ : Jet \\ $m$ : Mean \\ $M$ : Metal \\ $S$ : Surrounding fluid.
}

\section{Additional Points}

Highlights. (i) Local intense expansion of droplets was observed without significant pressure pulse. (ii) $L / D$ ratio suggests a dependence on Froude number. (iii) Melt temperature has strong impact on fragmentation, which needs to be better embodied in the instability theories and models.

\section{Competing Interests}

The authors declare that there is no conflict of interests regarding the publication of this paper.

\section{Acknowledgments}

The authors are grateful to National Science and Technology Major Project of China for providing the financial support for this study (2011ZX06004-008 and 2011ZX06004-024).

\section{References}

[1] R. Sairanen, G. Berthoud, G. Ratel et al., "OECD research programme on fuel-coolant interaction steam explosion resolution for nuclear applications-SERENA," Final Report, Organisation for Economic Co-Operation and Development, Paris, France, 2007.

[2] M. L. Corradini, B. J. Kim, and M. D. Oh, "Vapor explosions in light water reactors: a review of theory and modeling," Progress in Nuclear Energy, vol. 22, no. 1, pp. 1-117, 1988.

[3] S. K. Wang, C. A. Blomquist, and B. W. Spencer, "Modeling of thermal and hydrodynamic aspects of molten jet/water interactions," in Proceedings of the ANS National Heat Transfer Conference, vol. 4, pp. 225-232, 1989.

[4] J. W. Miles, "On the generation of surface waves by shear flows. III. Kelvin-Helmholtz instability," Journal of Fluid Mechanics, vol. 6, no. 4, pp. 583-598, 1959.

[5] M. Bürger, S. H. Cho, E. V. Berg, and A. Schatz, "Breakup of melt jets as pre-condition for premixing: modeling and experimental verification," Nuclear Engineering and Design, vol. 155, no. 1-2, pp. 215-251, 1995.

[6] C. V. Sternling and L. E. Scriven, "Interfacial turbulence: hydrodynamic instability and the marangoni effect," AIChE Journal, vol. 5, no. 4, pp. 514-523, 1959.

[7] M. Saito, K. Sato, and S. Imahori, "Experimental studies on penetration behaviours of water jet into freon-11 and liquid nitrogen," in Proceedings of the National Heat Transfer Conference, p. 173, Houston, Tex, USA, July 1988.

[8] J. P. Schneider, M. J. Marciniak, and B. G. Jones, "Breakup of metal jets penetrating a volatile liquid," in Proceedings of the 5th International Topical Meeting on Reactor Thermal Hydraulics (NURETH-5 '92), vol. 2, pp. 437-449, September 1992.

[9] T. N. Dinh, V. A. Bui, R. R. Nourgaliev, J. A. Green, and B. R. Sehgal, "Experimental and analytical studies of melt jet-coolant interactions: a synthesis," Nuclear Engineering and Design, vol. 189, no. 1, pp. 299-327, 1999.

[10] K. H. Bang, J. M. Kim, and D. H. Kim, "Experimental study of melt jet breakup in water," Journal of Nuclear Science and Technology, vol. 40, no. 10, pp. 807-813, 2003.

[11] Y. Abe, T. Kizu, T. Arai, H. Nariai, K. Chitose, and K. Koyama, "Study on thermal-hydraulic behavior during molten material and coolant interaction," Nuclear Engineering and Design, vol. 230, no. 1-3, pp. 277-291, 2004.

[12] Y. Abe, E. Matsuo, T. Arai et al., "Fragmentation behavior during molten material and coolant interactions," Nuclear Engineering and Design, vol. 236, no. 14-16, pp. 1668-1681, 2006.

[13] Y. Iwasawa, Y. Abe, A. Kaneko et al., "Effect of solidification on molten material jet behavior in coolant," in Proceedings of the 22nd International Conference on Nuclear Engineering, Prague, Czech Republic, July 2014.

[14] I. Huhtiniemi and D. Magallon, "Insight into steam explosions with corium melts in KROTOS," Nuclear Engineering and Design, vol. 204, no. 1-3, pp. 391-400, 2001.

[15] I. K. Park, J. H. Kim, S. H. Hong et al., "An investigation of the particle size responses for various fuel-coolant interactions in the TROI experiments," Nuclear Technology, vol. 161, no. 1, pp. 45-56, 2008.

[16] D. Magallon and I. Huhtiniemi, "Corium melt quenching tests at low pressure and subcooled water in FARO," Nuclear Engineering and Design, vol. 204, no. 1-3, pp. 369-376, 2001.

[17] R. Meignen and G. Berthoud, "Fragmentation of molten fuel jets," in Proceedings of the International Seminar on Vapour Explosion and Explosive Eruptions, p. 83, Sendaï, Japan, May 1997.

[18] M. Epstein and H. K. Fauske, "Applications of the turbulent entrainment assumption to immiscible gas-liquid and liquidliquid systems," Chemical Engineering Research and Design, vol. 79, no. 4, pp. 453-462, 2001.

[19] T. A. Dullforce, D. J. Buchanan, and R. S. Peckover, "Selftriggering of small-scale fuel-coolant interactions: I. Experiments," Journal of Physics D: Applied Physics, vol. 9, no. 9, pp. 1295-1303, 1976.

[20] D. Magallon and H. Hohmann, "Experimental investigation of $150-\mathrm{kg}$-scale corium melt jet quenching in water," Nuclear Engineering and Design, vol. 177, no. 1-3, pp. 321-337, 1997.

[21] E. Matsuo, Y. Abe, K. Chitose, K. Koyama, and K. Itoh, "Study on jet breakup behavior at core disruptive accident for fast breeder reactor," Nuclear Engineering and Design, vol. 238, no. 8, pp. 1996-2004, 2008.

[22] A. Kaiser, W. Schütz, and H. Will, PREMIX Experiments PM12PM18 to Investigate the Mixing of a Hot Melt with Water, FZKA, 2001. 

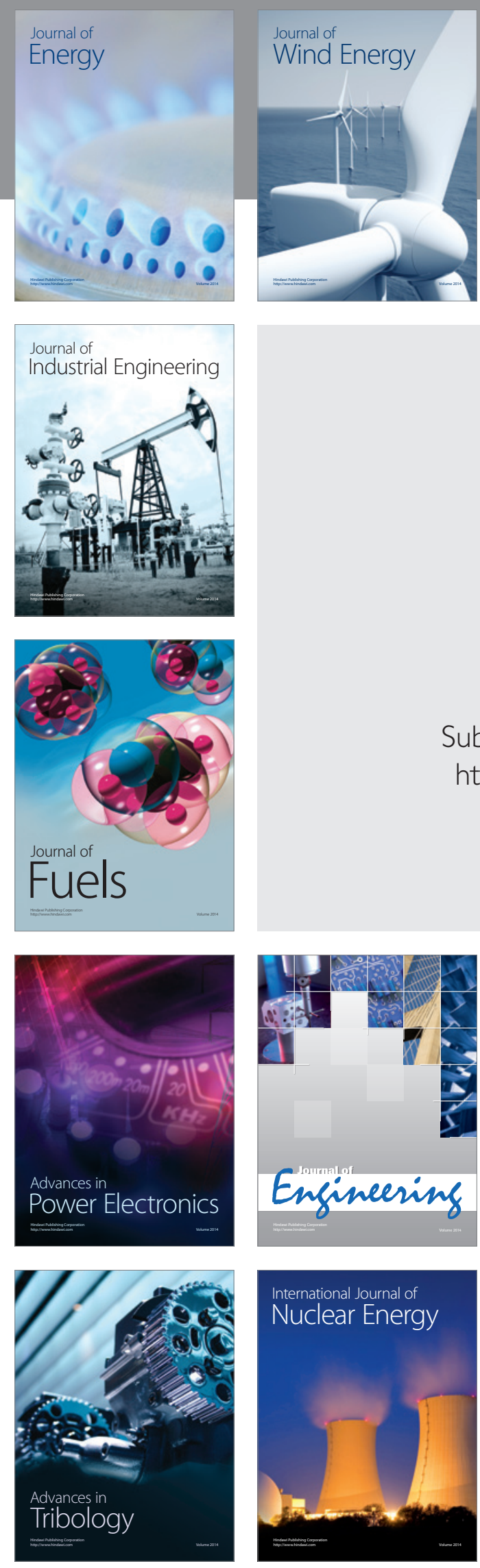

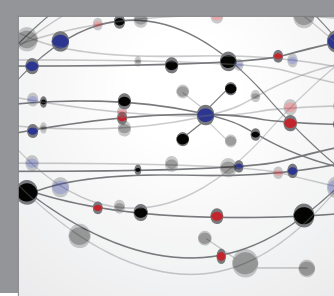

The Scientific World Journal
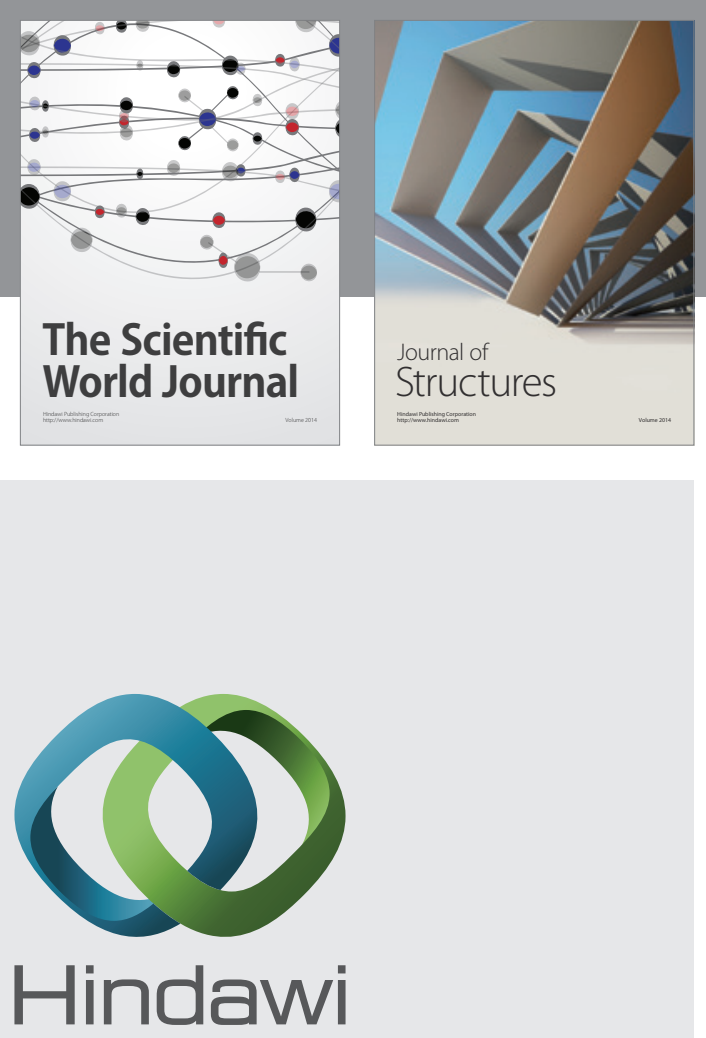

Submit your manuscripts at

https://www.hindawi.com
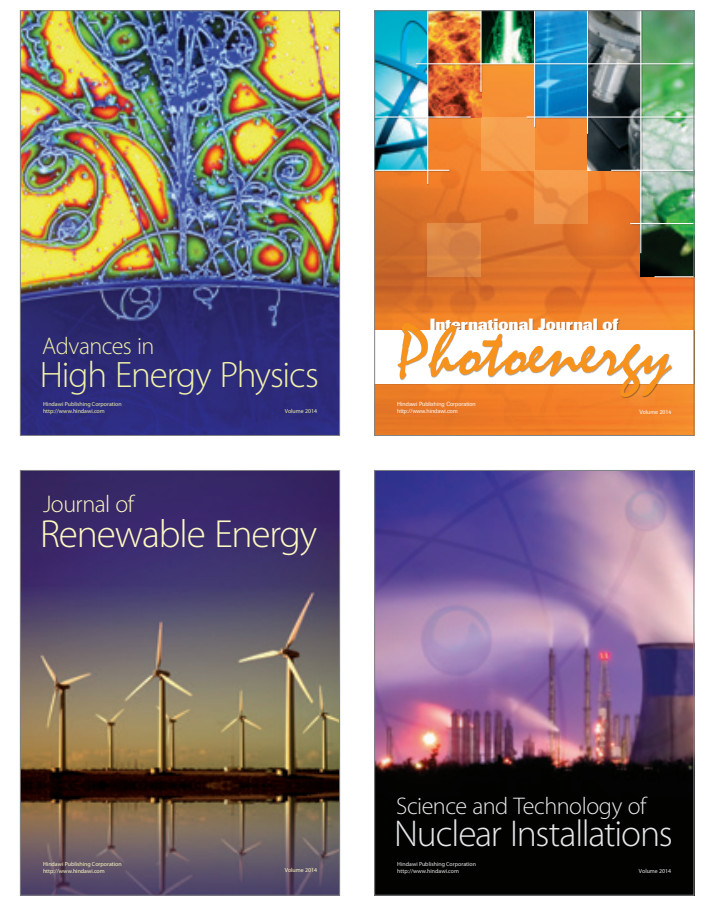
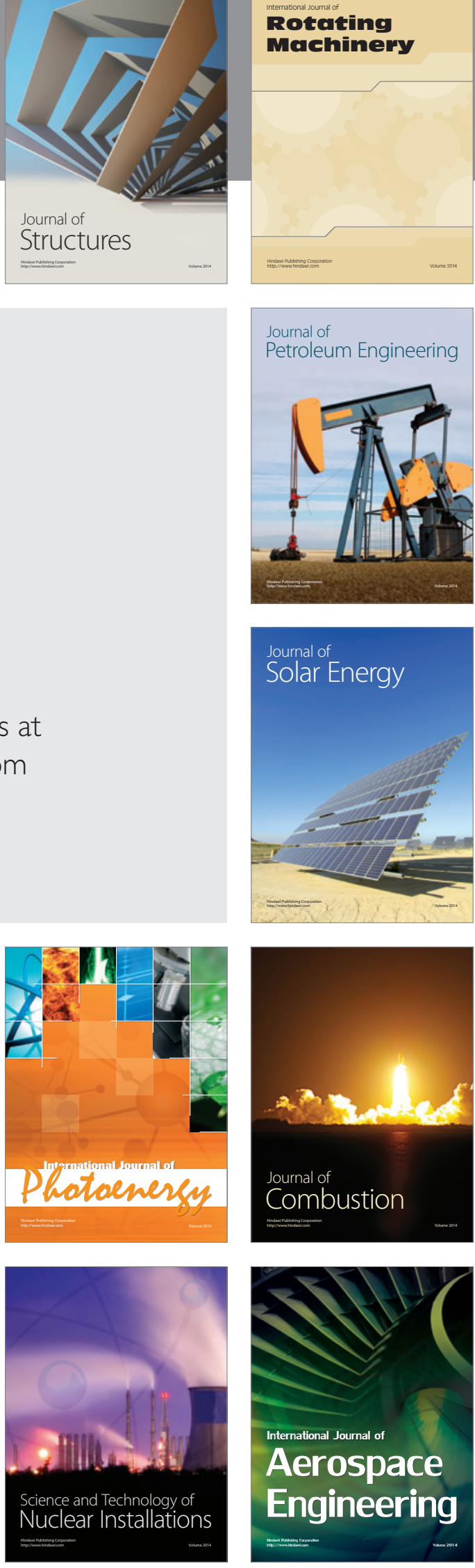